\title{
A formação médica em debate: perspectivas a partir do encontro entre instituição de ensino e rede pública de saúde ${ }^{*}$
}

Bruno Mariani de Souza Azevedo ${ }^{1}$

Sabrina Ferigato ${ }^{2}$

Tadeu de Paula Souza ${ }^{3}$

Sergio Resende Carvalho ${ }^{4}$

AZEVEDO, B.M.S. et al. Medical education under debate: perspectives from the intersection of teaching institutions and the public healthcare system. Interface Comunic., Saude, Educ., v.17, n.44, p.187-99, jan./mar. 2013.

This study relates to examination of medical education in Brazil and its current challenges at its intersection with the public healthcare system. It is a part of a broader qualitative participatory study entitled "Evaluative research on management of the work process and training of healthcare undergraduates and workers: exploring the boundaries". We present a historical review of medical education in Brazil in order to explore its present-day ramifications, by analyzing the empirical experience of implementation and monitoring of the discipline of Public Health, which has developed in-service. The results presented are laid out along five axes: i) work process; ii) educational function of the training; iii) clinical practice; iv) influence of the healthcare system on the university; v) curriculum reform.

Keywords: Medical education. Higher education. Public health system
Este trabalho refere-se ao estudo da formação médica no Brasil e seus desafios atuais no encontro com a rede pública de Saúde; recorte do estudo qualitativoparticipativo mais amplo intitulado "Pesquisa avaliativa sobre a gestão do trabalho e a formação de graduandos e trabalhadores de saúde: explorando fronteiras". Apresentamos uma retrospectiva histórica da formação médica brasileira para, posteriormente, explorarmos seus desdobramentos na atualidade, tendo como analisador a experiência empírica de implementação e acompanhamento de uma disciplina de Saúde Coletiva que se desenvolve em serviço. Os resultados apresentados são dispostos a partir de cinco eixos:

i) processo de trabalho; ii) função formadora do estágio, iii) prática clínica; iv) A rede intervindo na Universidade; v) reforma curricular.

Palavras-chave: Educação. Ensino. Saúde Coletiva.

\footnotetext{
* Elaborado com base em Carvalho (2010); pesquisa financiada pela Fapesp e aprovada pelo Comitê de Ética da Faculdade de Ciências Médicas, Unicamp. ${ }^{1-3}$ Doutorandos em Saúde Coletiva, Departamento de Saúde Coletiva, Faculdade de Ciências Médicas, Universidade Estadual de Campinas (FCM/

Unicamp). Rua Tessália Vieira de Camargo,

$126,2^{\circ}$ andar, sala 74. Caixa Postal 6111. Cidade Universitária "Zeferino Vaz". Campinas, SP, Brasil. 13.083-970. marianiazevedo@ gmail.com ${ }^{4}$ Departamento de Saúde Coletiva, FCM/ Unicamp.
} 


\section{Introdução}

As transformações históricas das práticas em saúde e da formação médica ensejam a discussão da função das instituições de ensino para com a realidade sociossanitária e com o Sistema de Saúde no Brasil. Isso porque cada concepção político-pedagógica adotada por essas instituições interfere diretamente para a efetividade ou não das políticas de saúde, propiciando, em maior ou menor grau: o desenvolvimento da autonomia do estudante, seu espírito crítico, seu compromisso social com o público, e seu ethos como profissional da saúde comprometido com mudanças.

A concepção de saúde e como ela é produzida nas instituições formadoras influem diretamente sobre as práticas de cuidado e sobre o papel do médico na sociedade.

Neste sentido, os espaços formativos, sejam eles a universidade ou os serviços, se constituem como um espaço de embates constantes entre as escolhas políticas, éticas e pedagógicas, elevando o grau de importância de todos os atores presentes no processo educativo e na determinação dos possíveis caminhos a serem adotados pela política de saúde e de formação pessoal (Oliveira, Koifman, 2004).

Partindo deste cenário complexo, discutiremos aspectos históricos, políticos e institucionais da formação médica tendo como foco os resultados gerados pela pesquisa intitulada: "Pesquisa Avaliativa Sobre a Gestão do Trabalho e a Formação de Graduandos e Trabalhadores de Saúde: explorando fronteiras", realizada no período de janeiro de 2008 a abril de 2010 - que teve como objetivo geral investigar os desafios da inclusão das temáticas: Saúde Coletiva, Clínica e Gestão, no currículo médico.

Dentro deste amplo campo, delimitaram-se, como foco de investigação, os movimentos em torno da construção e operacionalização da disciplina "Saúde Coletiva: Gestão e Planejamento em Saúde" (SC/GP) da Faculdade de Ciências Médicas da Unicamp (FCM/Unicamp).

Ao longo da pesquisa, foi posta em questão uma série de fatores, como: os programas teóricos da universidade, a proposta pedagógica da Saúde Coletiva na graduação da FCM/Unicamp e em outras Universidades, sua coerência metodológica com a grade curricular, e as possibilidades de integração entre os conteúdos da Saúde Coletiva e os ministrados pelas áreas clínicas.

Para melhor apresentar o problema da pesquisa, faremos um breve recuo histórico a respeito da formação médica, enfatizando o seu processo de especialização desde a publicação do relatório Flexner até a constituição do atual formato da atenção em saúde e as mudanças nas metodologias de ensino em saúde. Posteriormente, realizaremos articulações com os resultados da pesquisa.

\section{A formação médica: aspectos históricos e políticos}

Após a reforma do ensino médico americano, a partir do início do século $X X$, e a publicação do relatório Flexner, o Brasil foi gradativamente transformando seu currículo num progressivo deslocamento do modelo de referência de educação médica francês para o norte-americano sob a influência crescente das concepções marcadamente positivistas (Nunes 2010; Kemp, Edler, 2004). Essa transformação culminou com a reforma Universitária de 1968, na qual o modelo de ensino médico adotado foi, declaradamente, o modelo flexneriano (Machado, 1997), mas que refletia uma tendência expressa nas escolas médicas brasileiras desde a década de 1940 (Azevedo, 2012).

Foram então reforçados os estudos dos sistemas e órgãos do corpo humano, a individualização/ biologização do processo de adoecimento, e o ensino por disciplinas segundo especialidades. Além disso, foram criados os Hospitais Universitários como lócus estratégico e privilegiado para o binômio ensino-pesquisa. Esse processo, que foi estimulado pelo complexo médico-industrial, favoreceu uma especialização precoce de estudantes. Estes são submetidos a uma formação médica pautada pelo ensino disciplinar estanque e fragmentado, sob a influência da lógica do mercado de bens e serviços de saúde.

Neste cenário, projetos que privilegiam a formação de profissionais com perfil generalista se defrontam com a resistência de setores interessados na conservação deste modelo.

As consequências diretas desse processo se manifestam no privilégio de investimentos em ações curativas, hospitalocêntricas, com ênfase desproporcional no uso de tecnologias duras (equipamentos, logística, normatizações etc.) (Merhy, 2000). Associado a isso, observa-se um consequente descuido com práticas integrais e com o trabalho interdisciplinar em rede. Neste cenário, de modo geral, as 
escolas médicas passam, cada vez mais, a privilegiar o ensino de técnicas, habilidades e competências que tem como objetivo intervir sobre a saúde do indivíduo, enfatizando, neste, desequilíbrios biológicos e funcionais (Azevedo, 2012; Schraiber, 1989).

Potencializa-se, aqui, a entrada em um círculo vicioso que, muitas vezes, não é coerente com práticas que busquem produzir saúde. Recursos técnico-científicos ditos "de ponta" passam a ser, cada vez mais, demandados pelos profissionais com anuência de usuários. O alto custo destas tecnologias onera o sistema público e, indiretamente, constitui um estímulo à expansão do setor suplementar da saúde. Médicos, empresas privadas (e, em muitos casos, do setor estatal) e o complexo industrial consolidam, neste processo, uma aliança que tem um forte impacto sobre a formação e sobre as práticas dos médicos. Estas forças do mercado tensionam o campo de práticas e colocam em questão o compromisso ético com a produção da saúde que, em nível discursivo, constitui um dos pilares da profissão médica (Machado, 1997).

Este projeto tecnoassistencial, embora hegemônico, disputa sentidos com outros projetos societários e sanitários. Entre estes, destacamos, no Brasil, o projeto contra-hegemônico da Saúde Coletiva brasileira, que, embora apresente no seu interior distintas posições, é possível apontar, como tendência, a busca de um projeto tecnoassistencial que busca resistir e reinventar as práticas de produção da saúde e o sentido da formação e do fazer médico.

A partir de acúmulos históricos e de produções teórico-práticas após os anos 1970, a Saúde Coletiva consolida, em encontros e documentos legais - VIII Conferência Nacional de Saúde de 1986, a Constituição de 1988 (artigos 196 a 200, Capítulo da Saúde da Constituição Federal de 1988) e nas leis orgânicas da saúde de 1990 (Brasil, 1990,1988) - os princípios e diretrizes que fundam e orientam o desenvolvimento do Sistema Único de Saúde (SUS). Esses princípios fazem referência ao que se entende como processo saúde-doença, o objeto de ação e as bases para as políticas de formação de pessoal na área da saúde. Derivam, daqui, dois marcos importantes para o que aqui investigamos: a consolidação do SUS como ordenador da formação de recursos humanos na saúde (Brasil, 1988), e a legitimação dos determinantes sociais para orientar as formulações e práticas de cuidado em saúde.

A partir da década de 1990, observamos inúmeros núcleos de investigação, em parceria com serviços de saúde, aprofundando estas diretrizes, buscando enfrentar e oferecer alternativas para os projetos hegemônicos junto às práticas cotidianas nos serviços de saúde. Carvalho (2005) e Silva (1998), entre outros, abordam estas formulações quando discutem alguns dos principais projetos alternativos no interior da Saúde Coletiva: Defesa da Vida, Vigilância à Saúde, Ações Programáticas e de Promoção à Saúde. Projetos que seguem presentes nas práticas cotidianas em novas formulações, convivendo e, paradoxalmente, em alguns casos, incorporando elementos do projeto biomédico-flexneriano.

Estas formulações irão, nas décadas posteriores, permear vários dos debates no campo da Saúde no Brasil. Este processo irá se acelerar quando, a partir de 1994, começa a se implementar um programa de expansão da Rede Básica através de projetos como: o Programa de Saúde da Família (Bueno, Merhy, 1996), de Equipes de Referência (Carvalho, Campos, 2000), que propõe um novo formato organizativo para a Atenção Básica em conjunto com outras frentes de ação.

Ao mesmo tempo, movimentos como a CINAEM (Comissão Interinstitucional Nacional de Avaliação do Ensino Médico) e entidades como a ABRASCO (Associação Brasileira de Saúde Coletiva), a ABEM (Associação Brasileira de Educação Médica), a DENEM (Direção Executiva de Estudantes de Medicina) e a Rede Unida influenciam a construção de políticas do Ministério da Saúde, buscando formular uma pauta que contribua para as mudanças no ensino médico. As disputas políticas, tecnoassistenciais e pelos modos de formar os trabalhadores ocorrem neste duplo movimento paralelo.

Novas diretrizes curriculares são aprovadas a partir de 2001, com o intuito de produzirem impacto na formação médica. Buscando qualificar a formação e contribuir para a melhoria da assistência prestada aos usuários do SUS, foi elaborada legislação específica (Brasil, 2001b) e implementados programas direcionados ao assunto (Brasil, 2005a, 2005b, 2004, 2002), que buscam responder às necessidades do setor saúde.

Além do arcabouço legal do SUS, estas têm como fonte de inspiração a Lei de Diretrizes e Bases da Educação Nacional (Brasil, 2001a), que propõe a substituição do "currículo mínimo" pelas "diretrizes curriculares", as quais, ao se aterem ao estabelecimento de competências e habilidades, abriram um 
leque de possibilidades para iniciativas que buscam responder aos complexos desafios postos pelo cotidiano dos serviços de saúde.

A resolução que institui as Diretrizes Curriculares Nacionais do curso de Medicina define princípios, fundamentos, condições e procedimentos para a formação dos médicos. Preconiza que cada profissional deva assegurar que sua prática seja realizada de forma integrada e contínua com as demais instâncias do sistema de saúde, e que seja capaz de pensar criticamente, de analisar os problemas da sociedade e de procurar soluções para os mesmos. Recomenda, no artigo $3^{\circ}$, que o curso de graduação em Medicina tenha como egresso um médico com formação generalista, humanista, crítica e reflexiva, capacitado a atuar, pautado em princípios éticos, no processo de saúde-doença em seus diferentes níveis de atenção, com ações de promoção, prevenção, recuperação e reabilitação à saúde, na perspectiva da integralidade da assistência, com senso de responsabilidade social e compromisso com a cidadania, como promotor da saúde integral do ser humano (Brasil, 2001a).

Partindo-se destes pressupostos, é sugerido o desenvolvimento de programas de Ensino Superior que viabilizem a interação ativa do aluno com a população e com os profissionais de saúde desde o início da graduação, com o objetivo de proporcionar, ao estudante, a oportunidade de trabalhar sobre problemas reais, assumindo responsabilidades crescentes como agente formulador e prestador de cuidados compatíveis com seu grau de autonomia (Brasil, 2005b).

Esta breve síntese sobre as políticas tecnoassistenciais no SUS e sua relação com a temática do ensino reforça a existência de disputas entre a formação médica e os projetos políticos que procuram propor a reorganização do trabalho em saúde com um compromisso com a defesa da vida.

Neste campo de disputa, torna-se fundamental, para os setores que apostam na mudança do status quo, redefinir estratégias e processos de formação dos futuros médicos. Conteúdos que abordem a integralidade da saúde de forma efetiva, que contribuam para o desenvolvimento da capacidade de escuta, de acolhimento, de construção de vínculos, de abordagens interdisciplinares e de corresponsabilização, assumem grande importância.

É neste cenário que se constituiu a disciplina "Saúde Coletiva: Gestão e Planejamento em Saúde" (SC/GP) na FCM/Unicamp, objeto da presente pesquisa.

\section{Objeto e campo de investigação}

A disciplina SC/GP teve início em 2004, como um módulo do internato no qual grupos de cinco alunos (24 grupos em um ano letivo) frequentam o estágio durante dez dias úteis, cumprindo um total de quarenta horas-aula. Na maioria das vezes, a disciplina se desenvolve de tal forma que os alunos são encarregados, com apoio dos professores, de elaborarem Projetos Terapêuticos Singulares (PTS), demandados por uma equipe de saúde, que tenham como objeto indivíduos ou coletivos em situação de vulnerabilidade, buscando aprimorar a intervenção dessa equipe. O estágio ocorre, principalmente, em Unidades Básicas de Saúde do município de Campinas (Carvalho, Campos, Oliveira, 2009).

O internato em Gestão e Planejamento se orienta por diretrizes que afirmam que a gestão e a clínica se inserem num mesmo campo problemático, e que a "função docente" é compartilhada com trabalhadores e gestores; que devem contribuir, durante e após o estágio, para a qualificação de processos de trabalho nas unidades de saúde, e que ressaltam uma vivência, por parte dos alunos, da complexa dinâmica da produção de saúde no SUS, valorizando o trabalho em equipe e a produção de linhas de cuidado em rede (Azevedo, 2012).

Como explanado na introdução, no curso de Medicina há um forte aporte pedagógico concentrado nas especialidades, e o principal campo de estágio é o hospital. Dessa forma, um dos aspectos que interessava avaliar, na pesquisa citada, foi como vem sendo recebida, pelos alunos, docentes, trabalhadores e gestores da saúde, uma proposta pedagógica voltada para uma abordagem generalista, interdisciplinar e com direção na construção de redes, tomando a Atenção Básica (AB) como sua ordenadora. Para isso, a disciplina trabalhada por tal processo investigativo pareceu-nos interessante por se propor a ter um compromisso com uma forma de ensino que estimula a inserção dos graduandos na $A B$ - estratégia formativa fundamental para orientar os processos de mudança no modelo assistencial em saúde. 
Neste cenário, ao escolher como objeto de análise uma disciplina que sintetiza aspectos importantes da formação em serviço, valorizamos uma metodologia de pesquisa qualitativa e participativa em saúde.

\section{Considerações metodológicas: marco teórico-conceitual}

De acordo com Denzin e Lincoln (2006), a palavra qualitativa implica uma ênfase sobre as qualidades das entidades, sobre os processos e os significados que não são examinados ou medidos experimentalmente em termos de quantidade, intensidade ou frequência. Eles ressaltam que a competência da pesquisa qualitativa é o mundo da experiência vivida, por isso, todo trabalho de pesquisa que se define como qualitativo deve levar em conta a complexidade histórica do campo e o contexto do objeto pesquisado.

Desta forma, o desafio de acompanhar, pesquisar e avaliar os encontros entre os diferentes sujeitos envolvidos com a formação em saúde tem a necessidade de um aporte metodológico que inclua suas demandas, valores, desejos e conflitos que se fazem presentes neste processo. Pesquisar esses processos na Saúde Coletiva é investigar o que dá expressão aos modos de produção de cuidado, escutar os seus "ruídos", seus incômodos, fazer aparecer as coisas que estão ali (Franco, Merhy, 2009).

Alguns autores (Contandriopoulos, 2006; Furtado, Onocko Campos, 2005; Furtado, 2001; Silva, Formigli, 1994; Guba, Lincoln, 1989) enfatizam a necessidade de se incluírem diferentes e divergentes pontos de vistas, por meio da participação de representantes dos grupos de interesse no processo da pesquisa, uma vez que a realidade avaliada se constitui de fatores que possuem distintos valores para cada grupo de interesse. Entendem que a inclusão de diferentes grupos possibilita, ao mesmo tempo, pôr em cena objetivos específicos aos grupos envolvidos e traçar pontos problemáticos comuns aos grupos, exigindo a construção de uma superfície de análise transversal aos diferentes atores envolvidos, estabelecendo uma rede de discussão e análise, acionando a reflexão coletiva de pontos problemáticos.

A metodologia, constituída em torno do princípio ético da inclusão e da participação, neste trabalho, possibilitou a colocação em análise das relações de poder existentes entre gestores, trabalhadores, docentes, estudantes e pesquisadores, sendo estratégica, portanto, a proposta adotada de se pensar a avaliação como um dispositivo (Furtado, 2001).

Tomar a disciplina SC/GP como ponto de partida desta pesquisa permitiu que problematizássemos o processo de formação na relação com a rede de saúde, evocando a participação dos diferentes atores que compõem esta trama de relações: graduandos, docentes, trabalhadores e gestores de saúde.

Ao se porem em cena os ruídos do cotidiano, produzem-se, em potência, movimentos inventivos que questionam as posições instituídas, apontando para novas práticas de produção e defesa da vida (Merhy, 1997).

Partindo-se deste ideário ético-metodológico, a pesquisa foi organizada em três momentos: coleta de dados e sistematização das informações; validação das informações levantadas, e análise e devolução dos resultados.

O processo de coleta de dados ocorreu, sobretudo, através dos grupos focais e dos diários de campo de observadores participantes, dentro de uma perspectiva metodológica de triangulação de métodos (Minayo, 2006).

Os grupos focais foram divididos por grupos de interesse específico (trabalhadores, gestores, discentes e professores) e organizados a partir de diferentes eixos norteadores, que buscaram analisar diferentes vetores do processo de formação: Efeitos da construção compartilhada do PTS entre alunos e equipe; Elementos a serem enfatizados no processo ensino-aprendizagem; Utilização de recursos intersetoriais para o estágio e a relação com outros serviços; Necessidade de implementação de recursos na unidade para a inserção da disciplina; Relação entre trabalhadores, alunos e docentes a partir da entrada da disciplina na unidade; o papel dos profissionais na formação de futuros trabalhadores da Saúde Pública. Foram realizados 12 grupos focais.

Os diários de campo foram feitos a partir do acompanhamento de três turmas de estágio, dentro de uma perspectiva de observação participante, no qual, ao final de cada turma, foi possível refletir sobre alguns aspectos levantados durante a pesquisa de campo. 
As transcrições das gravações dos grupos focais e os diários de campo foram sistematizados, compondo um primeiro material que denominamos de um "primeiro grau de análise", pois este material, apesar de limitar-se a um exercício de síntese, já se faz a partir de recortes que refletem a priorização do pesquisador segundo suas análises. Foram constituídos quatro "textos-sínteses" (um texto de trabalhadores, um de alunos, um de gestores e um de docentes).

A segunda fase foi o momento de validação dos dados sistematizados com os diferentes grupos de interesse, gerando uma rodada de análise coletiva acerca do material produzido. Os textos-sínteses foram apresentados aos trabalhadores em reuniões de equipe das próprias unidades de saúde e, para os gestores, em reuniões do Distrito de Saúde Sudoeste, e os discentes tiverem esse material enviado por e-mail depois que as tentativas de reuni-los não tiveram sucesso.

Esta etapa possibilitou discutir e "validar" as narrativas e, ao mesmo tempo, aprofundar alguns pontos controversos. A partir desta estratégia, os grupos puderam fazer apontamentos sobre os aspectos abordados, possibilitando destacar novas abordagens sobre o material produzido. Essa rodada de validação gerou um novo material que buscou articular os pontos transversais aos diferentes grupos, compondo uma única narrativa que não se identificava com nenhum grupo específico, mas que agregava pontos críticos comuns aos diferentes grupos.

Neste segundo texto, buscou-se mais uma interferência analítica, fazendo aparecer, de forma mais presente, as percepções do próprio pesquisador, gerando o que denominamos de um "segundo grau de análise", que já apresentava algumas conclusões acerca dos problemas pesquisados.

A terceira etapa da pesquisa se constituiu em torno da metodologia de devolução dos resultados da pesquisa que, seguindo dentro de uma perspectiva participativa, compôs a conclusão da pesquisa a partir da realização de uma oficina. O termo "oficina", empregado para esta etapa da pesquisa, seguiu uma coerência metodológica, em que sua função pode ser descrita em duas perspectivas: fazer a devoluç̧ão dos resultados da pesquisa; servir como espaço de construção de proposições frente às questões apontadas.

Nesse sentido, "oficina" busca designar uma tarefa de construção de propostas que se abrem para além de funções formais de devolução de resultado estrito senso, mas como uma estratégia importante para ampliar para questões e atores não previstos nos grupos focais, gerando uma zona de passagem entre o fim da pesquisa e a continuidade dos processos avaliados.

\section{Resultados e discussão}

Os resultados da pesquisa foram organizados segundo âmbitos sistematizados na oficina avaliativa final, e constituem narrativas que expressam as perspectivas dos diferentes grupos de interesse em relação aos seguintes eixos: processo de trabalho das unidades; função formadora do estágio; prática clínica; reforma curricular.

\section{A disciplina e o processo de trabalho nas unidades}

A escolha dos casos clínicos que serão investigados pelos alunos normalmente é feita pela equipe, cujo principal critério de escolha é a dificuldade no manejo e a gestão clínica do caso. Nestes momentos, o estágio se apresenta como uma oferta para os trabalhadores, na medida em que alunos e professores ajudam na elaboração de PTS e de linhas de cuidados. Por outro lado, essa construção exige participação da equipe, o que interfere na dinâmica de trabalho, sendo vista por muitos profissionais como aumento da demanda de trabalho.

Esse aspecto é percebido não somente durante o estágio, como, também, na saída dos estudantes da unidade. Os trabalhadores questionam sobre a continuidade do acompanhamento dos casos quando o estágio acaba. Segundo eles, os estagiários oferecem uma atenção "mais intensiva e exclusiva aos casos", o que gera uma demanda que, muitas vezes, não é possível de ser mantida pelos trabalhadores.

Outro ponto sinalizado pelos profissionais de saúde refere-se ao fato de se sentirem mais observados e julgados pelos estagiários no seu trabalho quando questionados por estes. 
A inserção dos estudantes na unidade demanda um cuidado das instituições envolvidas. Às vezes, os horários da universidade e serviço de saúde são conflitantes, nestes casos, os trabalhadores declaram: "Não tem como organizar uma reunião de equipe extraordinária porque a Unicamp precisa de um caso!". Esta dificuldade de negociação dos tempos, em alguns momentos, é percebida pelos alunos como um descuido, como uma falta de organização das equipes para recebê-los.

Por outro lado, os trabalhadores, docentes e gestores enfatizam que a troca de conhecimento a partir da relação ensino-serviço gera a possibilidade de o trabalhador se envolver mais com o caso estudado, dando apoio às equipes quando os recursos se esgotam, além de ajudar a pensar em outras ações e estratégias não pensadas anteriormente. Enfatiza-se que os casos acompanhados pelas turmas anteriores são frequentemente lembrados pelos docentes, o que, em alguma medida, força a equipe a manter ou retomar uma assistência prestada, cujo acompanhamento, muitas vezes, não é possível.

Os trabalhadores, gestores e docentes avaliam que, quando se discute um caso com os alunos, seria preciso deixar um profissional para que avalie o andamento do PTS, o que não ocorre na maioria dos casos. As equipes declaram que ainda não se apropriaram dessa continuidade. Porém, todos os envolvidos colocam que essa dificuldade de sustentação não é gerada apenas pela disciplina, uma vez que a entrada dos alunos põe em análise a dinâmica de trabalho das unidades.

\section{A função formadora do estágio}

O trabalhador tem uma participação na formação de futuros profissionais, e seu atual protagonismo é bem maior do que em relação a alguns anos, mas essa participação ainda é vista como "pontual". Dentre os diferentes momentos formativos bastante destacados, podemos apresentar algumas posições dos diferentes atores da pesquisa.

Os alunos frisam a importância das visitas domiciliares e o contato com o território, possibilitando conhecer realidades socioculturais antes desconhecidas. Embora eles considerem que o estágio tenha relevância para sua formação profissional, a grande maioria não almeja trabalhar nestas unidades.

Para gestores e trabalhadores, o estágio é importante por apresentar o SUS como um campo de trabalho possível para os estudantes de Medicina. Na percepção dos trabalhadores, embora a maioria dos alunos não deseje trabalhar na rede pública, muitos acabam sendo empregados na Atenção Básica, dando importância para a apresentação da rede assistencial e da clínica ali praticada. Neste caso, os profissionais sentem mais facilidade para trabalhar com aqueles que passaram por este estágio do que com aqueles que não passaram.

Para gestores e trabalhadores, as equipes não estão instrumentalizadas para contribuírem na formação em saúde; apesar de esta ser uma diretriz do SUS, a construção de espaços para a capacitação de formadores/tutores para essa atividade é recente e ainda necessita de maiores investimentos e precisa ser mais bem construída organizacionalmente.

Os distintos atores concordam que o encontro entre estagiários, docentes e trabalhadores se constitui como um espaço de construção de parceria, uma troca onde ambos são formados na vivência da técnica e na teoria.

Muitas vezes, há um tensionamento entre os diferentes grupos de interesse, que se evidencia ora por meio de certa "desqualificação" do aluno em relação ao trabalho da equipe local, uma postura acadêmica distante, ora por uma postura dos trabalhadores de evidenciarem desconforto pela presença dos estagiários.

\section{O estágio e a prática clínica}

Para os alunos, um dos principais pontos da disciplina são as atividades "extra consultório" e as atividades práticas junto à equipe do Centro de Saúde. Destacam a visita domiciliar como um exemplo de prática que contribui para a construção de uma visão mais ampliada do modo de vida do paciente.

Os trabalhadores e gestores enfatizam que é importante, para o médico, conhecer o território. Levanta-se, também, a importância de se constituir um vínculo mais duradouro com o usuário. Pode-se acompanhar a pessoa em vários aspectos: no caso de uma pessoa acamada, os alunos veem "o lado 
dela, como ela passa a noite, como ela é acompanhada, como ela é tratada em seus vários aspectos, incluindo o uso de remédios e para além deles".

Alguns grupos de profissionais destacam a função clínico-pedagógica do caminhar com os alunos pela comunidade como um momento de trocas, no entanto, percebe-se uma dificuldade de incluir o médico neste processo. Isso gera uma cena contraditória em que os estudantes de medicina se veem diante de estratégias clínicas importantes que raramente têm a participação dos médicos.

Os docentes falam da importância e das dificuldades de se trabalhar com PTS, pois aparece como um "estorvo" no curso, pois exige um olhar mais cuidadoso com o que está sendo trabalhado, diferenciando-se da lógica da necessidade de "conduta imediata" presente na medicina, enfatizando a construção de um olhar problematizador para os casos junto com a equipe, avaliando e construindo os instrumentos que estão sendo utilizados a partir da prática com os casos.

É demarcada uma diferença entre discutir uma demanda da equipe ou uma demanda gerencial. Às vezes, não se sabe se deve ser discutida a clínica dos casos ou uma demanda mais ampla e generalizada, como uma questão da rede ou de evento sentinela. O PTS e a ênfase na constituição do cuidado em rede procura aproximar clínica e gestão, mas os docentes destacam que é difícil fazer a composição entre alunos, professores e trabalhadores, pois os interesses são diversos e o tempo é curto. Também os angustia saber do caso um dia antes do início da disciplina, com falta de programação e de recursos. "Interagir com a equipe, aplicar o PTS e fazer isso correndo é uma dificuldade metodológica, mas também dá um 'barato'".

\section{A interferência da rede de saúde no cenário pedagógico e acadêmico}

Pelos grupos de interesse, é muito enfatizado que o tempo que os estagiários ficam na unidade é insuficiente e, muitas vezes, eles saem do estágio sem entender o funcionamento do serviço. Mas, apesar de curta, é uma passagem intensa, em função desta dedicação exclusiva para poucos casos.

Os trabalhadores e gestores não participam da discussão do currículo em geral e seus conteúdos, e pouco da construção de suas metodologias. Ainda é necessário melhorar a participação dos gestores na avaliação dos alunos, sendo que alguns apontam que isso é importante tanto para o gestor quanto para o trabalhador.

Outro aspecto pontuado por trabalhadores e gestores é que a experiência de quem está trabalhando na unidade "bate de frente" com algumas proposições teóricas, que ficam distantes da realidade, e que, muitas vezes, demanda um tempo de adaptação: "os alunos saem do sonho e veem o mundo real!".

Para eles, o trabalho em equipe também funciona como um espaço de formação, pois "ninguém consegue trabalhar sozinho". O trabalho dos médicos é visto como um processo que "está muito mecanizado".

Os trabalhadores ressaltam a descoberta de que são importantes para a formação dos alunos e do valor de não serem "um guia turístico". Os alunos enfatizam que também têm pouco tempo para avaliar o que estão fazendo e que o momento dos grupos focais da pesquisa foi muito importante, pois puderam participar da avaliação da disciplina emitindo suas opiniões livremente.

Percebemos que os estágios permitem colocar em análise o processo de trabalho nas unidades, porém é um pouco mais difícil para as equipes colocarem em análise a instituição formadora. Existe uma maior interferência da universidade sobre instituição saúde do que o contrário.

\section{O estágio dentro do cenário curricular}

Os alunos veem pouca relação entre as disciplinas de Saúde Coletiva nos diferentes anos da graduação $\left(1^{\circ}, 2^{\circ}, 3^{\circ}, 4^{\circ}\right.$ e $5^{\circ}$ anos). Apesar de ser "boa", a disciplina fica "jogada", "dispersa", não há comunicação entre os módulos, havendo quebra na continuidade do currículo. Destacam, ainda, que existe uma separação entre os estágios de gestão e clínica: o primeiro está mais ligado ao discurso "preventivista" e o segundo é mais focado em patologia, tratamento, diagnóstico e cirurgia; mas entendem que, no quinto ano, este estágio consegue articular estes dois aspectos. Percebem um avanço neste estágio pesquisado em termos de metodologia de ensino e conteúdo proposto. 


\section{Considerações finais}

A complexidade de uma transição curricular em instituições de ensino se deve ao peso da tradição e, igualmente, de uma complexa rede de relações de poder que se fazem presentes nessas instituições. Em nossa pesquisa, chegamos a resultados que se aproximam das análises expressas por Feuerwerker (2004) de que os currículos expressam justamente essas relações dentro das universidades, e que os processos de mudança apresentam propostas híbridas, que combinam tendências mais conservadoras com propostas reformistas. Se, por um lado, isso compõe as diferenças inerentes aos grupos humanos, também abre margem para contradições institucionais geradoras de antagonismos para o processo de ensino-aprendizagem, que perde em potência. Esses antagonismos se atualizam nas relações alunosdocentes; trabalhadores-alunos; docentes-trabalhadores etc.

Nesse sentido concordamos com a concepção de que a potência intercessora do encontro entre universidade e rede pública de saúde se define pela oportunidade de gerar trocas entre trabalhadores, docentes, gestores, alunos e usuários, ainda que de posições diferentes e com diferentes relações de poder (Garcia, 2009). Metodologias de ensino que trabalhem com análises coletivas de casos clínicos, construção conjunta de projetos terapêuticos e elaboração de diagnósticos multiprofissionais são oportunidade de se colocarem em debate as relações de poder que atravessam e compõem a relação ensino-serviço e possibilitam problematizar os antagonismos que criam falsas dicotomias, como: especialista-generalista; clínica-saúde coletiva; indivíduo-sociedade. Nesse sentido, faz toda a diferença os discentes e docentes estarem na rede enquanto parceiros de trabalhadores e gestores. A ideia aqui é a de que essa relação supere um formato de "franquia" da universidade no serviço, de forma que aquilo que os serviços de saúde produzam possa invadir a instituição de ensino, que escapa de sua lógica hegemônica de reprodução de seu modo de fazer, para além dos muros acadêmicos.

Seguimos com a avaliação de que esse encontro entre instituições de ensino e a rede de saúde é uma grande oportunidade para os discentes perceberem um modelo assistencial distinto do curativo, individual e hospitalocêntrico, tão tradicionalmente ressaltado no ensino em ambiente hospitalar (Albuquerque et al., 2008). Neste cenário, os alunos podem reconhecer a construção de outro modelo de atenção na integração de práticas em saúde. Nessa vivência também questionam os múltiplos avanços e insuficiências do SUS, possibilitando um aprendizado desde a organização do sistema até as práticas clínicas (Pinto, Formigli, Rego, 2007).

Atuando diretamente nos espaços de saúde, os discentes têm a oportunidade de perceber como são dinâmicas as relações de cuidado e de poder; conseguem desenvolver uma interpretação crítica do sistema de saúde, incomodar-se com ele e nele atuar mais implicadamente (Carvalho, Ceccim, 2006).

Convém ressaltar a importância do ensino em múltiplos espaços do sistema. Não pretendemos advogar que o sentido de formação que vamos propondo aqui seja apenas para a Atenção Básica, mas que isso também contamine outros serviços do sistema, provocando outra forma de ensino e serviço se relacionarem e produzirem a formação dos trabalhadores. Todos os nós da rede de saúde também podem ser espaços de cuidado produtores de vida e de formação ética.

No entanto, entendemos que exercício da prática médica na Rede Básica de saúde implica, potencialmente, o encontro com territórios de grandes dificuldades sociais e com a vida cotidiana que se opõe a cenários idealizados que muitos alunos constituem para si e para o exercício de sua profissão. A inserção em cenários reais e contraditórios não busca mascarar as dificuldades da rede pública, mas incluí-la como plano de problematização que ativa um questionamento do papel do médico frente a este cenário adverso.

Apesar desta avaliação, que aponta para reformas curriculares inovadoras, muitas vezes, verificamos que as mudanças ainda estão circunscritas à grade dos quatro primeiros anos da graduação. No internato, a grade curricular ainda é, quase totalmente, preenchida por disciplinas "clínicas" especializadas que têm como cenário prioritário o hospital. Por isso, julgamos que os temas trabalhados na disciplina estudada e sua estratégia metodológica não podem ficar restritos a ela, sendo necessário ampliar a sua proposta dentro do curso, tanto nas disciplinas da Saúde Coletiva quanto nas ministradas pelos demais departamentos. Defendemos que temáticas como: gestão da clínica/cuidado, clínica ampliada, projeto terapêutico singular, território e formação de redes e de linhas de cuidados, venham a 
constituir um dos eixos do currículo de graduação de profissionais em saúde, por tratarem de núcleos específicos de saber, abordarem metodologias de articulação entre os diferentes saberes e suas especialidades. Isso vai muito além da mera redistribuição de carga horária ou da invenção de novas disciplinas. Implica a mudança de conceitos, dos processos de ensino-aprendizagem, mudança nas relações de poder institucionais e na forma como as universidades entendem seu papel na contemporaneidade.

Trata-se de um salto qualitativo, onde a formação deve passar a ser gerenciada coletivamente, e a ser orientada pelas reais necessidades de saúde do nosso país. Para isso, é necessário desenvolver novas sensibilidades e operar com a participação de um corpo maior de docentes de distintas áreas de saber, em diálogo com a pluralidade de conhecimentos dentro e fora do universo acadêmico.

Sustentamos que uma das melhores formas de desenvolver esses conteúdos e práticas é a articulação efetiva entre instituição de ensino e rede de saúde. Essa perspectiva pedagógica inclui a participação de atores externos à universidade e à classe médica como elemento essencial na construção do processo formativo. Isso pode se dar a partir da criação de espaços para representantes dos serviços públicos e da população na universidade, ou a partir da inserção de graduandos, estagiários e docentes na rede por meio de contratos construídos de forma participativa, na construção conjunta dos sentidos que se quer produzir com esse encontro - mecanismos de gestão partilhada do processo de ensino-aprendizagem que aumentem o grau de interferência mútua entre universidade e serviços de saúde.

\section{Colaboradores}

Todos os autores trabalharam na construção do artigo, em suas etapas de formulação, redação e revisão.

\section{Referências}

ALBUQUERQUE, V.S. et al. A integração ensino-serviço no contexto dos processos de mudança na formação superior dos profissionais de saúde. Rev. Bras. Educ. Med., v.32, n.3, p.356-62, 2008.

AZEVEDO, B.M.S. O ensino da gestão no curso de graduação de Medicina da FCM/Unicamp: possíveis encontros entre universidade e serviços de saúde. 2012. Dissertação (Mestrado) - Faculdade de Ciências Médicas, Universidade Estadual de Campinas, Campinas. 2012.

BRASIL. Portaria Interministerial $n^{\circ} 2101$, de 3 de novembro de 2005: Institui o Programa Nacional de Reorientação da Formação Profissional em Saúde Pró-Saúde. Brasília: Ministério da Educação, Ministério da Saúde, 2005a.

Pró-saúde: Programa nacional de reorientação da formação profissional em saúde. Brasília: Ministério da Saúde, Ministério da Educação, 2005b.

AprenderSUS: o SUS e os cursos de graduação da área da Saúde. Brasília: Ministério da Saúde, Secretaria de Gestão do Trabalho e da Educação na Saúde, 2004. 
BRASIL. Programa de incentivos às mudanças curriculares para as escolas médicas PROMED. Brasília: Ministério da Saúde, Secretaria de Políticas de Saúde, Coordenação Geral da Política de Recursos Humanos, 2002.

Lei de Diretrizes e Bases da Educação Nacional. Brasília: Ministério da Educação, 2001a.

Resolução CNE/CES no 4, de 7 de novembro de 2001. Institui Diretrizes Curriculares Nacionais do curso de graduação em Medicina. Brasília: Ministério da Educação, Conselho Nacional de Educação, Câmara de Educação Superior, 2001b.

Lei $n^{\circ} 8080$, de 19 de setembro de 1990. Dispõe sobre as condições para a promoção, proteção e recuperação da saúde, a organização e o funcionamento dos serviços correspondentes. Diário Oficial da União, Brasília, DF, 1990. Seção 1, p. 18055.

Constituição da República Federativa do Brasil. Brasília: Senado Federal, 1988.

BUENO, W.S.; MERHY, E.E. Os equívocos da NOB 96: uma proposta com sintonia com os projetos neoliberalizantes?. Campinas: Departamento de Medicina Preventiva e Social, Unicamp, 1996. (Mimeogr.).

CARVALHO, S.R. Pesquisa avaliativa sobre a gestão do trabalho e a formação de graduandos e trabalhadores de saúde: explorando fronteiras. Campinas: Departamento de Saúde Coletiva, FCM/Unicamp, 2010.

Saúde coletiva e promoção da saúde: sujeito e mudança. São Paulo: Hucitec, 2005.

CARVALHO, S.R.; CAMPOS, G.W.S. Modelos de atenção à Saúde: a organização de equipes de referência na rede básica da secretaria municipal de saúde de Betim/Minas Gerais. Cad. Saude Publica, v.16, n.2, p.507-15, 2000.

CARVALHO, S.R.; CAMPOS, G.W.S.; OLIVEIRA, G.N. Reflexões sobre o ensino de gestão em saúde no internato de medicina na Faculdade de Ciências Médicas da Unicamp. Interface - Comunic., Saude, Educ., v.13, n.29, p.455-65, 2009.

CARVALHO, Y.M.; CECCIM, R.B. Formação e educação em saúde: aprendizados com a saúde coletiva. In: CAMPOS, G.W.S. et al. (Orgs.). Tratado de Saúde Coletiva. Rio de Janeiro: Hucitec, Fiocruz, 2006. p.149-82.

CECCIM, R.B.; FERLA, A.A. Abertura de um eixo reflexivo para a educação da saúde: o ensino e o trabalho. In: MARINS, J.J.N.; REGO, S. (Orgs.). Educação médica: gestão, cuidado, avaliação. São Paulo: Hucitec, 2011. p.258-77.

CONTANDRIOPOULOS, A.P. Avaliando a institucionalização da avaliação. Cienc. Saude Colet., v.11, n.3, p.705-11, 2006.

DENZIN, N.; LINCOLN, Y. O planejamento da pesquisa qualitativa: teorias e abordagens. Porto Alegre: Artmed, 2006.

FEUERWERKER, L.M. Gestão dos processos de mudança na graduação em Medicina. In: MARINS, J.J.N. (Org.). Educação médica em transformação: instrumentos para a construção de novas realidades. São Paulo: Hucitec, 2004. p.17-39. 
FRANCO, B.T.; MERHY, E.E. Mapas analíticos: um olhar sobre a organização e seus processos de trabalho. In: CARVALHO, S.R.; BARROS, M.E.; FERIGATO, S. (Orgs.). Conexões: saúde coletiva e políticas da subjetividade. São Paulo: Aderaldo \& Rothschild, 2009. p.301-21.

FURTADO, J. Um método construtivista para a avaliação em saúde. Cienc. Saude Colet., v.6, n.1, p.165-82, 2001.

FURTADO, J.; ONOCKO CAMPOS, R. A transposição das políticas de públicas de saúde mental no Brasil para a prática nos novos serviços. Rev. Latino- Am.

Psicopatol. Fund., v.8, n.1, p.109-22, 2005.

GARCIA, R. Parcerias entre instituições de ensino e serviços de saúde do distrito sudoeste de Campinas: um olhar sobre (des)encontros. 2009.

Dissertação (Mestrado) - Faculdade de Ciências Médicas, Universidade Estadual de Campinas, Campinas. 2009.

GUBA, E.; LINCOLN, Y. Fourth generation evaluation. Newbury Park: Sage Publications, 1989.

KEMP, A.; EDLER, F.C. A reforma médica no Brasil e nos Estados Unidos: uma comparação entre duas retóricas. Hist. Cien. Saude-Manguinhos, v.11, n.3, p.569-85, 2004.

MACHADO, M.H. Os médicos no Brasil: um retrato da realidade. Rio de Janeiro: Fiocruz, 1997.

MERHY, E.E. Um ensaio sobre o médico e suas valises tecnológicas: contribuições para compreender as reestruturações produtivas do setor saúde. Interface Comunic., Saude, Educ., v.9, n.16, p.109-16, 2000.

Em busca do tempo perdido: a micropolítica do trabalho vivo. São Paulo: Hucitec, 1997.

MINAYO, M.C.S. Pesquisa avaliativa por triangulação de método. In: BOSI, M.L.M.; MERCADO, F.J. (Orgs.). Avaliação qualitativa de programas de saúde: enfoques emergentes. São Paulo: Vozes, 2006. p.163-90.

NUNES, E.D. Cem anos do relatório Flexner. Cienc. Saude Colet., v.15, supl.1, p.956, 2010.

OLIVEIRA, G.S.; KOIFMAN, L. Integralidade do currículo de medicina: Inovar/ transformar, um desafio para o processo de formação. In: MARINS, J.J.N. et al. (Orgs.). Educação médica em transformação: instrumentos para a construção de novas realidades. São Paulo: Hucitec, 2004. p.143-64.

PINTO, L.L.S.; FORMIGLI, V.L.A.; RÊGO, R.C.F. A dor e a delícia de aprender com o SUS: integração ensino-serviço na percepção dos internos em Medicina Social. Rev. Baiana Saude Publica, v.31,n.1, p.115-33, 2007.

SCHRAIBER, L. Educação médica e capitalismo: um estudo das relações educação e prática médica na ordem social capitalista. São Paulo: Hucitec, 1989.

SILVA JUNIOR, A.G. Modelos assistenciais em saúde: o debate no campo da Saúde Coletiva. São Paulo: Hucitec, 1998.

SILVA, L.M.; FORMIGLI, V.L. Avaliação em saúde: limites e perspectivas. Cad. Saude Publica, v.10, n.1, p.80-91, 1994. 
AZEVEDO, B.M.S. et al.

AZEVEDO, B.M.S. et al. La formación médica en debate: perspectivas a partir de la relación entre institución de enseñanza y la red de salud pública. Interface - Comunic., Saude, Educ., v.17, n.44, p.187-99, jan./mar. 2013.

Este trabajo se refiere al estudio de la formación ,médica en Brasil e sus desafíos actuales en su relación con la red de salud pública, segmento de salud pública, segmento del estudio cualitativo - participativo más amplio titulado "Investigación evaluadora de la gestión del trabajo y la formación de graduandos y trabajadores de salud: Explorando Fronteras". Presentamos una retrospectiva histórica de la formación médica brasileña para explorar posteriormente sus desdoblamientos actuales, teniendo como analizador la experiencia empírica de implementación y acompañamiento de una disciplina de Salud Colectiva que se desarrolla en servicio. Los resultados se disponen a partir de cinco ejes: i) proceso de trabajo; ii) función formadora del periodo preparatorio; iii) práctica clínica; iv) la intervención de la red en la Universidad; v) reforma curricular.

Palabras clave: Educación. Enseñanza. Salud Colectiva. 